\title{
Cenários Futuros Para o \\ Desenvolvimento de Coleção de Moda Slow: \\ estudo de caso Brisa Slow
}

\section{Fashion}

- Anerose Perini 1

P.408-430 


\title{
Cenários Futuros Para o Desenvolvimento de Coleção de Moda Slow: estudo de caso Brisa Slow Fashion
}

\begin{abstract}
RESUMO
O presente artigo traz, como pronto de partida, cenários futuros para insights de design no desenvolvimento sustentável. Para isto, usou-se elementos da marca de moda feminina Brisa Slow Fashion e seu desenvolvimento de coleção. Foram traçadas questões referentes a tendências e megatendências sustentáveis, além do desenvolvimento de moda, eco desde sua ideação até o fim do ciclo de vida do produto. Delineado por uma pesquisa exploratória qualitativa, a discussão terá como base o estudo de caso da marca anteriormente citada. O objetivo principal é desenvolver possibilidades de ação da marca em cenários possíveis no espaço de tempo entre 5 a 15 anos.
\end{abstract}

Palavras-chave: Slow fashion, Coleção de moda sustentável, Cenários futuros.

\section{Future Scenarios for the Development of Slow Fashion Collection: Brisa Slow Fashion case study}

\begin{abstract}
This article brings, as a starter, future scenarios for design insights into sustainable development. For this, elements of the feminine fashion brand Brisa Slow Fashion and its collection development were used. Issues of sustainable trends and megatrends were drawn, as well as the development of fashion, eco-friendly from its idealization to the end of the product life cycle. Outlined by a qualitative exploratory research, the article is based on the case study of the brand previously mentioned. The main objective is to develop possibilities of brand action in possible scenarios in the time span between 5 and 15 years.
\end{abstract}

Keywords: Slow fashion, Sustainable fashion collection, Future Scenarios. 


\section{INTRODUÇÃO}

O presente artigo aborda questões referentes às tendências de consumo, vistas como apropriação e possibilidade de concretização em curto espaço de tempo pela população. Por vezes, são modificáveis ou adaptadas de acordo com a sociedade ou o contexto em que estão expostas. As tendências a curto prazo são utilizadas pela moda e bens de consumo, que têm, em seu cerne, produtos sazonais e renováveis de forma rápida, seguindo os modismos de lançamento impostos pelo mercado ou até mesmo por celebridades. Há também, tendências que se concretizam a longo prazo. Consideradas tendências de consumo ou macrotendências, são passíveis de modificação de acordo com o meio socioeconômico ou ambiental e tende a permanecer por anos vigendo na sociedade. Perante essa afirmação é importante frisar que megatendências voltadas à sustentabilidade emergem cada vez mais na sociedade do século XXI.

Tratando-se de pesquisa em design de moda, a metodologia do estudo foca-se no cunho qualitativo, pois elege as dinâmicas das megatendências sustentáveis e o desenvolvimento de coleção de moda sustentável com ciclo de desenvolvimento fechado. Para isso, foi privilegiado o estudo de caso, tendo como unidade de pesquisa a marca de moda feminina Brisa Slow Fashion, natural de Porto Alegre, incluindo sua essência e valores dentro do fenômeno contemporâneo slow fashion, e os possíveis cenários de atuação para a marca. Os cenários foram traçados pela autora Perini (2015; 2016) em sua dissertação de mestrado, e que posteriormente resultou no artigo "Cenários Futuros para o Design Sustentável". No artigo, a autora deixou em aberto, nas suas considerações finais, "[...] propostas 
para os cenários ligados à moda e a sustentabilidade, à evolução da sociedade no horizonte-tempo de 5 a 15 anos, no que se refere ao desenvolvimento de produtos limpos" (PERINI, 2016, p.11).

Por estes parâmetros buscou-se definir os objetivos do artigo, partindo das megatendências sustentáveis. O objetivo geral para o artigo ficou assim estabelecido: "desenvolver possibilidades de ação da marca em cenários possíveis"; enquanto que os objetivos específicos ficaram dessa forma estipulados: compreender como se desenvolve a megatendência sustentável; descrever o desenvolvimento de uma coleção de moda slow; e, por fim, traçar possibilidades de ação da marca através de suas premissas e valores em cenários futuros, no espaço de tempo entre 5 a 15 anos.

Questões norteadoras, como complexidade e cenários, serão abordadas mediante a visão dos autores Morin (2011), Zurlo (2010), Perini (2015; 2016). As premissas que embasam as formas de expressão da sociedade, no desenvolvimento de macrotendências, terão o suporte dos autores Popcorn (1999; 2002), Caldas (2006), Penn (2008), Morace (2012). As questões de cunho social, sustentável e de ciclo de vida dos produtos estarão ancoradas em autores como Fletcher (2011), Manzini e Vezzoli (2011), Berlim (2012), Salcedo (2014) e Gwilt (2014).

\section{TENDÊNCIAS E CENÁRIOS}

Para iniciar o desdobramento sobre tendências e cenários é necessário compreender suas estruturas complexas. Segundo Morin (2011), a complexidade deve ser simplificada para que se tenha compreensão do todo. "[...] A simplificação é necessária, mas deve ser relativizada [...] a redução consciente de que ela é redução, e não redução arrogante que acredita possuir a verdade simples, atrás da multiplicidade e complexidade das coisas" (MORIN, 2011, p.102). A complexidade, ainda segundo o autor, é uma forma estratégica que auxilia as empresas em sua 
organização e possíveis previsões de ação. Esse pensar estratégico busca o que não está claro a olhos nus, conhecido por "invisível por trás do fenômeno".

[...] o pensamento complexo integra o mais
possível os modos simplificadores de pensar,
mas recusa as consequências mutiladoras,
redutoras, unidimensionais e finalmente
ofuscantes de uma simplificação que se
considera reflexo do que há de real na
realidade (MORIN, 2011, p.6).

Tal técnica é abordada por Deni como "aspectos imateriais e a intersecção de valores intangíveis" (2008 apud MORAES, 2010, p.19). Considerados os enfoques de Morin (2011) e de Deni (2008) compreende-se que não existem formas corretas ou direcionadas para se prever o futuro e sim fenômenos complexos imprevisíveis que podem ser antecipados com certo grau de assertividade.

Por esse mesmo viés, Zurlo (2010) aponta que "[...] cenários futuros possíveis [...] usam capacidade para organizar e tornar compreensíveis os dados de contexto com suporte das escolhas" (ZURLO, 2010, p.11). Perini (2015), por sua vez, reflete sobre a necessidade de compreender a complexidade local, através das diversas formas de representação socioculturais a fim de "[...] construir modelos simplificados da realidade local, com foco em seu desenvolvimento dentro de um curto e longo espaço de tempo [...]" (PERINI, 2015, p.33). Para isso é necessário compreender os símbolos e signos dentro das estruturas complexas e "capturar suas informações relevantes" para a construção de cenários e assim, conceber de forma plausível informações reais, possíveis ou imaginárias (PERINI, 2015, p.36). Os signos e símbolos, por sua vez, definem-se por sinais como o "fato imediatamente perceptível que nos faz conhecer uma coisa a propósito de outra que não o é" (CALDAS apud GREIMAS, 2006, p.92).

Portanto, os signos e significados complexos traduzidos e reduzidos em categorias, tornam-se cenários. Por muitas vezes, esses cenários tendem a antecipar possibilidades de "agir de forma estratégica", 
para empresas e designers em suas criações e abordagem junto aos consumidores. "Esses cenários, se bem-sucedidos, crescem com grande influência para o futuro, sendo importante criar um equilíbrio dinâmico entre espécies e seu ambiente, em constante evolução" (PERINI, 2015, p.37).

Quando criados, os cenários devem ser revisitados sempre que possível, pois os movimentos complexos da sociedade podem influenciar em seu desenvolvimento. Morin (2010) afirma que "inovações/ criações produzem transgressões que podem ampliarse e potencializar-se em tendências, que tanto podem infiltrar-se na tendência dominante e modificar sua orientação quanto substituí-la" (MORIN, 2010, p.16). Os cenários preveem as tendências como as propostas por Popcorn (1999):

A melhor forma de ver os indícios precoces das "novas" tendências é entender a evolução das tendências atuais. As tendências percorrem diferentes estágios mapeáveis. Até seu desaparecimento, a tendência terá sofrido muitas transformações (POPCORN,1999, p.161).

De forma similar a Popcorn (1999), Caldas (2006) afirma que a "[...] configuração dessa fuga permanente em direção ao futuro que nos aguarda, para o qual por meio de atração irresistível. [...] passa a ser representada como desdobramento 'natural' do presente" (CALDAS, 2006, p.34).

Contudo, Morin (2010) propõe que as "[...] invenções, inovações, criações técnicas, culturais e ideológicas surgem e modificam a evolução [...]". Essas premissas sobre as tendências são complexos modelos que "[...] se desenvolvem ao destruir antigas estruturas, culturas e instituições" (MORIN, 2011, p.16). As transformações sociais que modificam as tendências podem acontecer casualmente ou por pequenos epifenômenos sociais/locais. Um exemplo trazido por Penn (2008, p.237) é a tendência "volta as raízes", que apareceu após o ataque terrorista em 11 de setembro de 2001 nos EUA. Depois do fatídico evento, mudanças nos comportamentos sociais geraram maior expressão aos feitos artesanais, 
familiares e do "faça você mesmo". Atitudes que visavam respeitar o tempo de cada pessoa para a execução de práticas manuais, a volta às raízes familiares e conhecimentos locais, a concentração, aptidão e o relaxamento mental. Essa prática impactou diretamente nos conceitos de desenvolvimento artesanal e sustentável, com respeito ao tempo de realizar os feitos, criando assim um objeto de valor agregado e, por vezes, mais sustentável.

De forma similar a Penn (2008), Morace (2012) propõe o início do "Terceiro Renascimento", que consiste em valores guiados pela cultura mais sustentável que norteia as experiências em valores percebidos pelos consumidores.

A sustentabilidade constitui, atualmente, o
tema da reflexão e desenvolvimento que
majoritariamente estimula investimentos
econômicos e psíquicos. O Silicon Valley se
transformou num lugar onde a Terceira
Renascença é guiada pelas qualidades
ambientais das inovações a estas dedicadas. A
chave ganhadora resulta naquela
sustentabilidade vivida em termos emocionais
e não ideológicos, através da qual os projetos
são vividos como enriquecimento da própria
integridade pessoal (MORACE, 2012, p.19).

Morin (2010) afirma que as tendências só se confirmam quando existem seguidores que tendem a aceitá-las. Da mesma forma, Caldas adverte que "[...] outro ponto fundamental é a ideia de crença: está claro que a tendência só poderá existir se houver uma predisposição dos indivíduos à crença naquilo que a tendência representa" (CALDAS, 2006, p.47).

Em sua definição sobre tendências para a moda, Salcedo (2014) aponta "[...] um sistema que faz com que os consumidores se sintam atraídos a comprar coisas novas a cada temporada [...]". O que acaba por concretizar $o$ modelo de tendências passageiras e efêmeras. "[...] Esse sistema cria necessidade de mudança constante, consumo contínuo e acúmulo, cada vez maior de roupas a serem descartadas [...]" (SALCEDO, 2014, p.41). Contudo, Caldas propõe que a moda é um fenômeno social que possibilita a 
previsibilidade de consumo, como fenômeno da cadeia de casualidades, das quais "[...] indicadores qualitativos e quantitativos, cujos movimentos reais, substituídos na cadeia casual, permitam obter as previsões" (CALDAS, 2006, p.49).

Para o presente estudo são abordadas duas megatendências de comportamento que auxiliam no desenvolvimento sustentável em coleções e produtos/matéria prima e serviços ligados a marcas de moda. Como apontado por Faith Popcorn (2002), no livro "Dicionário do futuro", são levantadas questões que permeiam as formas de economia, educação, meio ambiente e consumo, entre outros assuntos recorrentes na sociedade, em diversas formas de expressão. Uma das questões destacadas no capítulo "Marketing e economia de consumo", trás a referência ao "Sem crueldade" (2002, p.222), que aponta o crescimento da moda ecológica sem maus tratos aos animais, meio ambiente e pessoas. A autora reafirma a informação de que o consumo e a importância dos cuidados com a natureza, no capítulo "Meio ambiente", e subseção "Lavagem cerebral verde" (2002, p.266), é o viés no qual os consumidores irão apoiar as marcas cidadãs, sua pegada verde, desde o plantio das fibras naturais, mão de obra local, fornecedores eco e formas de distribuição sem impacto ambiental. As questões abordadas nas megatendências por Pocorn (2002) trazem para a moda comportamentos de consumo que podem caracterizar possibilidades de criação ecossustentáveis, tanto para as coleções de moda quanto para design.

Seguindo a mesma vertente, Berlim (2012) adverte que alguns cenários sustentáveis se tornaram estabilizados com o tempo, como o "Fair Trade" conhecido por Mercado Justo, "[...] considerado uma das maiores e mais importantes ferramentas da sociedade" (BERLIM, 2012 p.51). Iniciativa nascida nos anos 60 que propõe o mercado colaborativo, desde comunidades em situações de risco, e amplia o mercado para artesões e cooperativas agirem no mercado de forma justa. Existem ainda quatro cenários sustentáveis, sendo dois cenários ligadas à temática de 
"compartilhamento" e dois cenários ao "design emocional". Esses, por sua vez, já existem como microtendências locais que, todavia, estão em construção para possível expansão.

As tendências sustentáveis de desenvolvimento de coleção para as marcas de moda são apresentadas por Gwilt (2014) como "[...] propostas de minimizar os impactos socioambientais associados à moda" (GWILT, 2014, p.22). Seja em oportunidades de escolhas de materiais na criação de redes colaborativas de cooperativas locais ou, ainda, repensando no ciclo de vida do produto e, até mesmo, na distribuição e coleta após o uso/descarte. Para a criação de design ético importa seguir formas expressivas de comunicação, para que o consumidor compreenda o que a marca almeja e estabeleça um relacionamento empático com a peça de roupa. Essas questões transformam os enfoques da lógica do consumo de valor agregado e símbolos para a marca junto ao consumidor.

\subsection{Cenários possíveis para Porto Alegre}

A pesquisa base usada como pano de fundo para o presente artigo pertence aos estudos da autora Perini (2016). A autora apresenta reflexões sobre a pesquisa local e criação de cenários para a cidade de Porto Alegre no horizonte-tempo de 5 a 15 anos, que "[...] influi na mudança de estilo de vida na cidade, e tem os ciclistas como força motriz para a ressignificação de um objeto como meio de transporte, modificando assim o contexto do perímetro urbano [...]" (PERINI, 2016, p.1).

A autora sinaliza, em seu estudo sobre design e mobilidade urbana sustentável, que objetos/artefatos podem ser ressignificados pela sociedade, de acordo com as questões de apropriação. Afirma também que os artefatos tem o poder de influenciar questões de ordem, valor e sentido. Tais questões são variáveis de acordo com o contexto, o ambiente e o coletivo, e intensificam a apropriação de sentido de um artefato inserido na sociedade. 
O uso desses artefatos tende a modificar suas características e relações, fortalecendo os signos culturais. Para a presente pesquisa evidencia-se o uso da bicicleta no perímetro urbano da cidade de Porto Alegre, sendo esse artefato um meio de interação entre usuários e observadores, reafirmando signos pertencentes ao objeto e gerando estímulos sociais, por exemplo: a qualidade de vida nos cuidados com o corpo e a saúde, a sustentabilidade, a vida em sociedade, a proximidade com a natureza, a liberdade de ir e vir (PERINI, 2016, p.4).

Embora existam outras questões sustentáveis além da mobilidade urbana por bicicleta, Perini (2015) adverte que bens e serviços podem sofrer alterações de sentido de acordo com a forma que as pessoas usufruem das cidades. A partir desse viés de compreensão da sociedade e suas complexidades locais, optou-se por criar possíveis cenários futuros visando a ação de empresas e insigths para designers. Entretanto, para traçar os cenários, a autora realizou entrevistas com diversos nichos em Porto Alegre para avaliar as necessidades que a sociedade apresenta em seu cotidiano e as questões evolutivas do contexto. Portanto, pode-se observar que,

[...] existem tendências sustentáveis e necessidades de mudar costumes de vida e estilos de consumo. No que se refere ao desenvolvimento sustentável, a Comissão Mundial sobre o Meio Ambiente e Desenvolvimento (CMMAD) lançou, em 1991, o documento Our Common Future, atendendo ao objetivo de prevenir o futuro do ecossistema e da sustentabilidade e integrando estratégias ligadas ao desenvolvimento social, político e do ecossistema (PERINI, 2016, p.2).

No contexto de Porto Alegre, a autora traçou quatro possibilidades de ação para as empresas e designers, auxiliando na criação de insights para o desenvolvimento de produtos e serviços sustentáveis. Tais cenários tem como proposta orientar a compreender a complexidade sociocultural local, para estabelecer questões problemáticas e situações futuras, com a pergunta "como seria se?", utilizada por Manzini 
e Jègou (2006), pilares da criação dos cenários (PERINI, 2016, p.3).

O primeiro cenário provém da "cultura para a sustentabilidade", na conscientização da população em prol da sustentabilidade e o respeito ao meio ambiente, sendo possível a mobilização direcionada ao movimento slow e a retomada de valores socioculturais. Esse cenário contém o "[...] incentivo às economias locais, a valorização de experiências únicas, as trocas de conhecimento, a colaboração aberta $[\ldots]^{\prime \prime}$, tornando-se parte do cotidiano das cidades (PERINI, 2016, p.9).

O segundo cenário apresenta o "futuro tecnológico", com maior interação tecnológica entre as pessoas e as interações em rede, modificando os sistemas verticais e tornando-os horizontais, pois todos terão as mesmas possibilidades de interação e atuação em espaços públicos e/ou privados. Já o terceiro cenário apresenta a regressão social em seu comportamento fast, chamado de "sociedade em crise", na qual a autora sugere que "[...] o consumo exagerado e individualista poderá extinguir o ecossistema e seus territórios, e gerar o caos nas políticas públicas que não conseguirão reagir em tempo hábil e de forma coesiva entre a população e o contexto" (PERINI, 2016, p.10).

Entretanto, o quarto e último cenário, identificado como "território deteriorado", resulta nas precárias condições locais e políticas públicas defasadas, não apenas no contexto social mas também nas questões de meio ambiente, ambos desgastados. Nesse cenário são levantadas questões de insegurança, infraestrutura precária, além da poluição do ar, solo e água (PERINI, 2016, p.10).

As quatro possibilidades de cenários futuros mostram possibilidades oportunidades de ação em contextos diferentes. Mesmo em contextos cenários impróprios a proposta é de gerar ações para potencializar iniciativas sustentáveis, com sugestões de valor e significados que possam promover a cultura da sustentabilidade a partir do design.

Gwilt (2015) afirma que o designer tem participação em todas as etapas de pesquisa: pesquisa de tendências, escolha dos fornecedores, criação de 
coleção e, algumas vezes, durante os processos de confecção e expedição. A contextualização permite o entendimento de que as questões ligadas à sustentabilidade podem fazer parte das escolhas corretas para a redução dos impactos ambientais e sociais, causados pela indústria da moda. Manzini e Vezzoli (2011) propõe ainda que a possibilidade de sucesso nas escolhas de design "[...] não somente deve ser coerente com as perspectivas da sustentabilidade ambiental, mas deve também levar em conta as grandes transformações em ações da sociedade" (MANZINI e VEZZOLI, 2011, p.56).

Diante das questões abordadas acima, considerase verossímil a possibilidade de criar significados e valor agregado nos produtos desenvolvidos por designers, em consciência dos impactos ambientais, do uso dos materiais, processos mão de obra e descarte. Para isso, importa planejar projetos de design inovadores e originais, prezando a sustentabilidade ecológica e social desde seu princípio.

\subsection{Consciência e slow design}

Para o presente estudo a escolha recaiu por apresentar as tendências sustentáveis "slow". Segundo Berlim (2012), essas tendências estão em crescimento no sentido inverso ao declínio das tendências "fast". A sustentabilidade nas práticas sociais aparece como forma de expressão cultural através do movimento "slow", que oferece base para o desenvolvimento de uma sociedade ecológica com mais qualidade de vida, tornando-a sustentável, com respeito ao meio ambiente e aos seres que ali habitam. O movimento "slow", emerge na década de 80 com filosofia fundamentada no silogismo "do tempo certo para cada etapa cumprida". Para compreender o sentido do movimento "slow", Honoré (2012) destaca o nascimento dessa tendência na Itália, tornando-se aceita em grande parte das sociedades do planeta. As premissas do movimento "slow" trazem benefícios para a sociedade, pois transformam os estilos de vida e seu entorno. O "slow" deu origem a outras ramificações como, por exemplo, o 
movimento "slow fashion", que se propõe desenvolver coleções mais lentas atemporais. Atualmente, uma das vertentes originadas do "slow" é o "minimalismo", mas não com a proposta de oferecer roupas sóbrias e linhas retas como era sua essência nos anos 60. Mas sim, voltando o olhar para criação de roupas atemporais mais duráveis, que implica em restringir o consumo.

O termo "slow" é conceituado por Berlim (2012) e Salcedo (2014) como a moda lenta com maior consciência sobre seu impacto sobre as pessoas e ecossistema. Além do que, tenciona conscientizar todas as partes que participam no processo de realização das peças e de quem consome.

[...] o slow fashion enxerga o consumidor e seus hábitos como parte importante da cadeia. Ao contrário do que se poderia pensar, a moda lenta não é um conceito baseado no tempo, e sim na qualidade, que no fim, evidentemente, tem alguma relação com o tempo dedicado ao produto (SALCEDO, 2014, p.33).

Fletcher (2011) enfatiza que a moda lenta "[...] representa um conjunto distinto de atividades de moda para promover o prazer da variedade, a multiplicidade e a importância cultural da moda dentro dos limites biofísicos" (FLETCHER, 2011, p.128). Em paralelo, um dos desdobramentos do movimento "slow" é reconhecido por Eco Design, que surge como proposta criativa em meados dos anos 90. Segundo Gwilt (2015), o Eco Design apresenta questões associadas desde a criação da coleção e seus impactos efeitos ambientais até o fim da vida do produto. "O objetivo é evitar, reduzir ou eliminar os impactos que podem poluir, destruir ou reduzir os recursos naturais do planeta" (GWILT, 2015, p.19).

Mediante essas questões, o conceito de moda "slow" de Fletcher (2011) aponta mudanças drásticas, pois as coleções são pensadas em um ano inteiro e não por temporada ou estação, com produtos locais e peças quase personalizáveis ou colecionáveis. Além da mudança na criação das coleções, são contemplados tempos corretos para realização de cada etapa e distribuição. Também há distintos objetivos não 
relacionados às vendas, mas atrelados à confiança do cliente com a marca e aos valores emocionais, diferentes das propostas das marcas "fast".

\subsection{O desenvolvimento de produtos sustentáveis}

Independente do tamanho da empresa e sua gama de produtos, a sustentabilidade na moda é guiada por três pilares essenciais: sociedade, meio ambiente e economia. Gwilt (2015) assegura que o primeiro pilar é a manufatura, que deve manter direitos e condições trabalhistas garantidos. O segundo, referese ao meio ambiente, que tem como princípio a estabilidade ecológica. O terceiro, favorece a economia, que tem como base a viabilidade econômica de todos os envolvidos nos processos até o fim do ciclo de vida do produto.

Autores como Manzini e Vezzoli (2011) propõem que a escolha de materiais, processos e recursos de baixo impacto ambiental podem ser objetivos traçados no início dos projetos de design. Para isso, o designer tem papel primordial nas escolhas de soluções eficazes em prol do menor gasto de energia e de cuidados com a biosfera e geosfera (2011, p.92). Da mesma forma, Gwit (2015) apresenta as possíveis etapas para a criação de uma coleção de moda, e coloca o designer como o centro da tomada de decisão para cada etapa e para cada processo de desenvolvimento de produto (figura 1). A autora também considera relevante a sustentabilidade em todas as etapas, desde o início de criação da peça/coleção, seus fornecedores e durabilidade dos produtos; na construção dos moldes e costura das peças e na manufatura; na distribuição e o menor consumo de energia e vendas no varejo; das possibilidades de uso, conserto das peças ou reaproveitamento; até o seu descarte final, em reuso ou reciclagem. 


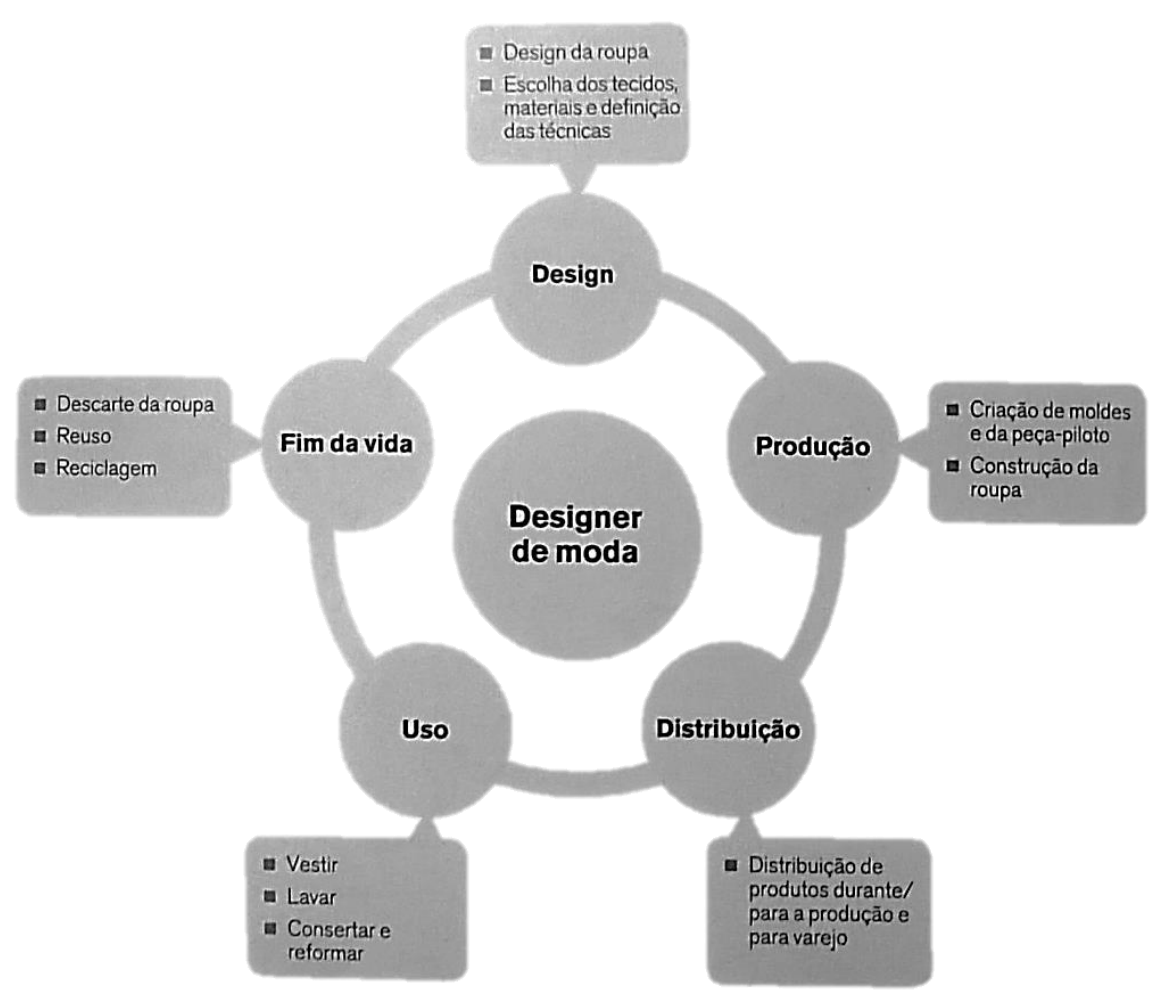

Figura 1: Ciclo de vida de uma peça de roupa de moda.

Fonte: GWILT (2015, p.32).

\section{ESTUDO DE CASO SLOW FASHION E O DESENVOLVIMENTO DE PRODUTOS SUSTENTÁVEIS}

Tendo como base o desenvolvimento de produtos sustentáveis sugerida por Manzini e Vezzoli (2011), Fletcher (2011) e Gwilt (2015), para a efetivação do estudo buscou-se uma marca que, em sua filosofia, seguisse o princípio de moda sustentável no desenvolvimento de uma coleção. Por opção, selecionou-se uma marca de Porto Alegre capaz de ser inserida no contexto dos cenários futuros traçados por Perini (2016), para validar a proposta de utilizar cenários futuros em uma marca de moda real.

A marca Brisa Slow Fashion nasceu no ano de 2016, na cidade de Porto Alegre, RS. Com produção em baixa escala de peças de alfaiataria e peças confortáveis para a mulher contemporânea, tem foco no consumo consciente e mão de obra especializada artesanal. A marca presa por tecidos nacionais orgânicos ou tecidos reciclados, além de tingimentos 


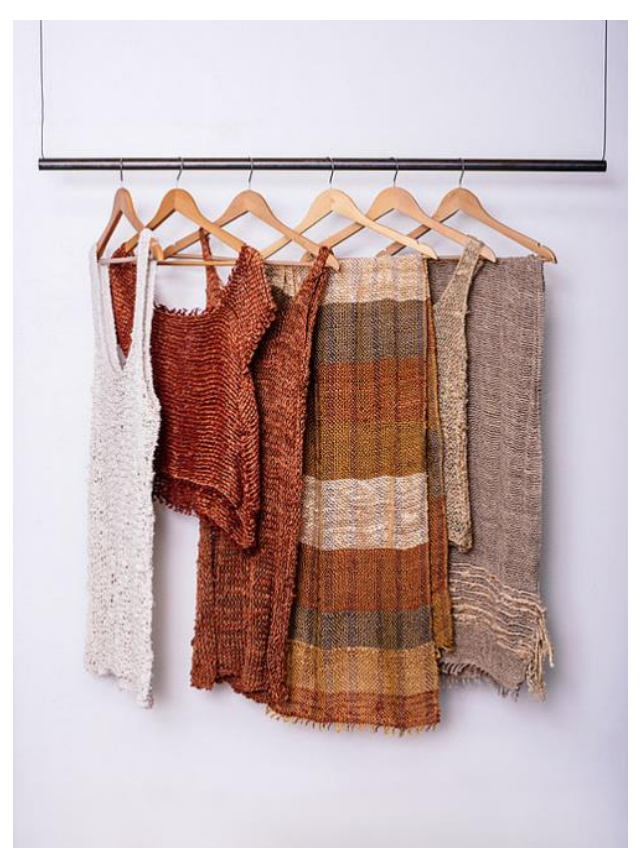

Figura 2: Malharia de tear artesanal. Fonte: Brisa Slow Fashion, 2018. naturais e técnicas manuais de beneficiamento das peças (Figura 2). Os produtos são criados com respeito ao meio ambiente, de forma consciente e com proposta de menor impacto possível. A marca preserva o desenvolvimento de mão de obra local e das cooperativas parceiras e busca fornecedores artesanais (AZEVEDO, p.14-17).

A partir dessas premissas, a designer Tatiana Stein, responsável pela marca, traçou parâmetros de um público alvo condizente com suas expectativas, que compreendesse a essência da Brisa Slow Fashion (Figura 3). Na entrevista para o site Vida de Amora, a designer descreve "A mulher Brisa é uma pessoa leve, simples, elegante, sincera, justa, verdadeira, confiante e otimista. É uma pessoa que enxerga além do que se vê, sente o valor dar coisas no imensurável" (VIDA DE AMORA, 2017).

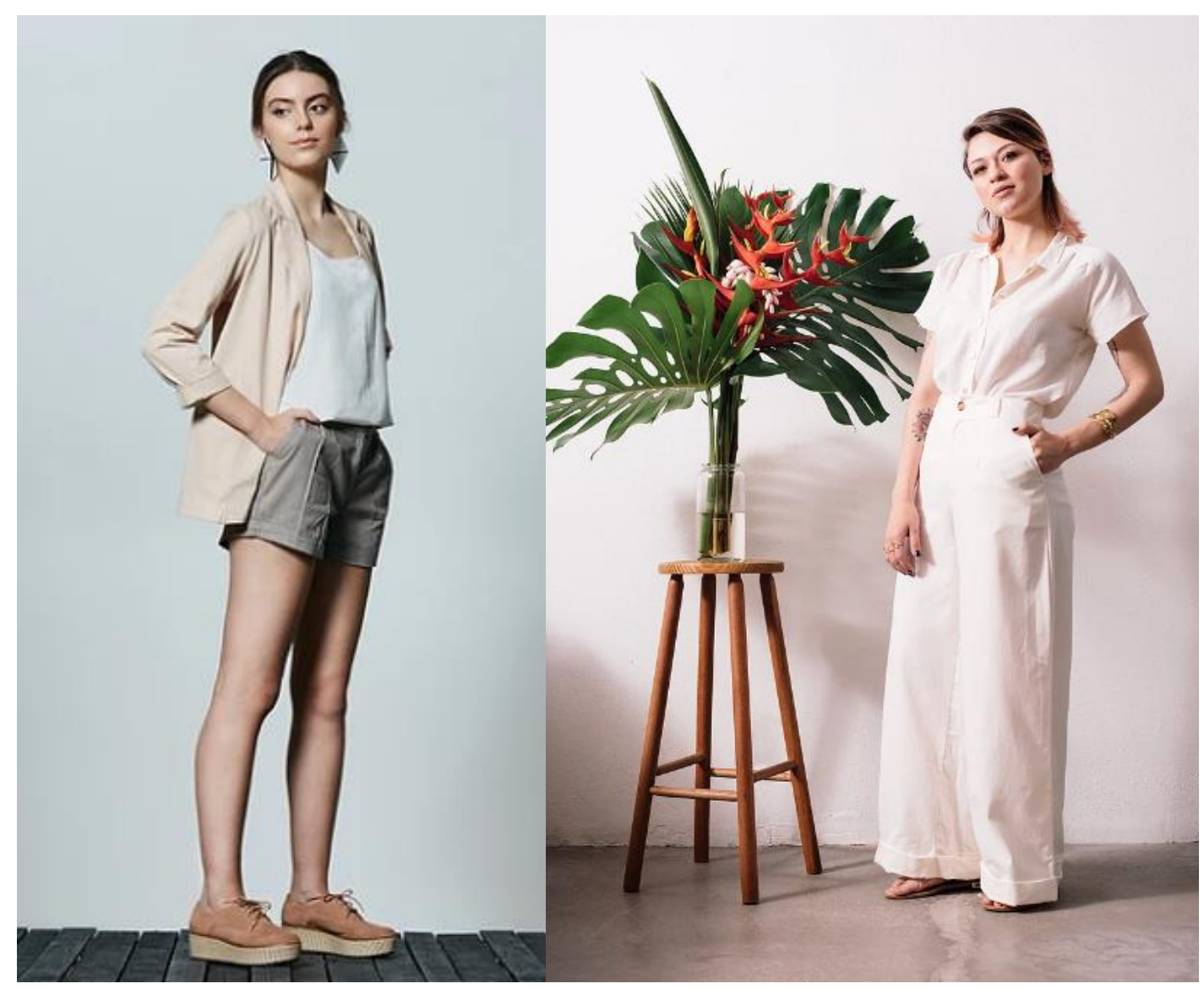

Figura 3: Editorial 1 e Editorial 4.

Fonte: Brisa Slow Fashion, 2018. 
A designer, e também fundadora da marca Brisa Slow Fashion, Tatiana Stein, realiza a criação e coordena todas as etapas, desde a pesquisa por fornecedores de tecidos orgânicos como, por exemplo, o Casulo Feliz e a Justa Trama², desenvolve peças em tear artesanal, busca parcerias para as etapas de modelagem e costura (Cooperativa Porto-alegrense Univens), além da própria designer realizar o tingimento natural das peças da coleção. Além disso, os produtos comercializados são vendidos com a proposta de um armário cápsula, com peças que combinem entre si e possam ser usadas em diversas ocasiões.

O armário cápsula da Brisa tem um mix de produto básico e necessário, que se mesclado nas cores atuais é possível utilizar as peças por muito tempo. Esse mix de produto é composto por: $t$ shirt, regata, blazer alongado e minimalista, short, calça, camisa over e vestido (VIDA DE AMORA, 2017).

O processo de coloração das peças é realizado totalmente de forma artesanal, com tingimento natural, sem agressão à natureza. Algumas vezes estão disponíveis para venda na loja as peças em algodão orgânico no tom natural, também conhecido como algodão cru, para que o cliente faça a escolha a cor da peça que tenciona adquirir.

Importante frisar que pelo fato de a Brisa Slow Fashion ter em seu DNA a criação de um produto mais duradouro e haver a possibilidade de tingir mais de uma vez a mesma peça, as criações da marca tem sua vida prolongada. Outra alternativa para descarte é a compostagem, já que os tecidos são orgânicos ou naturais, as cores das peças são de tingimento natural sem aditivos químicos e todas as linhas de costura usadas e aviamentos são biodegradáveis. As palavraschave que levam o desenvolvimento da marca são: "artesanal, justo, local, transparente, atemporal, sustentável, minimalista, orgânico, e comportável" (VIDA DE AMORA, 2017).

\footnotetext{
${ }^{2}$ A Justa Trama é reconhecida como a maior cadeia produtiva do Brasil no segmento de confecção da economia solidária, que valoriza o trabalho e a dedicação de cada pessoa envolvida no processo. (FTC).
} 
Após identificar como a marca aparece no mercado de moda e sua possível influência nos significados e valores sustentáveis, seguindo os princípios dos autores Manzini e Vezzoli (2011) e Gwilt (2015), fez-se o modelo de criação de coleção sustentável, apresentado na figura 4 . O modelo de criação da marca inicia na natureza e no público alvo como primeiro e segundo critérios para gerar a criatividade e inovação em produtos de design, seus impactos no ecossistema e seus processos de escolha como, por exemplo, em peças minimalistas para um armário cápsula.

A parte de produção, que engloba fornecedores e mão de obra, busca cooperativas e artesões locais, o que oferece maior qualidade $e$ durabilidade às peças, assim evitando sua obsolescência. Sob este critério, a marca acaba por investir em fornecedores e manufatura brasileira para incentivar economia local.

As redes de distribuição das peças compõem-se de lojas físicas e e-commerce, tendo como escolha de comunicação o marketing transparente, como propostas de aproximação com o cliente, que acaba por fomentar a cultura da sustentabilidade e os cuidados no manuseio das peças para sua maior durabilidade.

Para o fim do ciclo do produto são apresentadas possibilidades de retingimento da peça de roupa, agregando a possibilidade de reaproveitamento do produto para assim, iniciar um novo ciclo de vida. Ainda existe a possibilidade de descarte em compostagem, pois todos os materiais usados na confecção das peças são biodegradáveis. 
Figura 4: Modelo de criação de coleção sustentável.

Fonte: Desenvolvido pela autora, 2018.

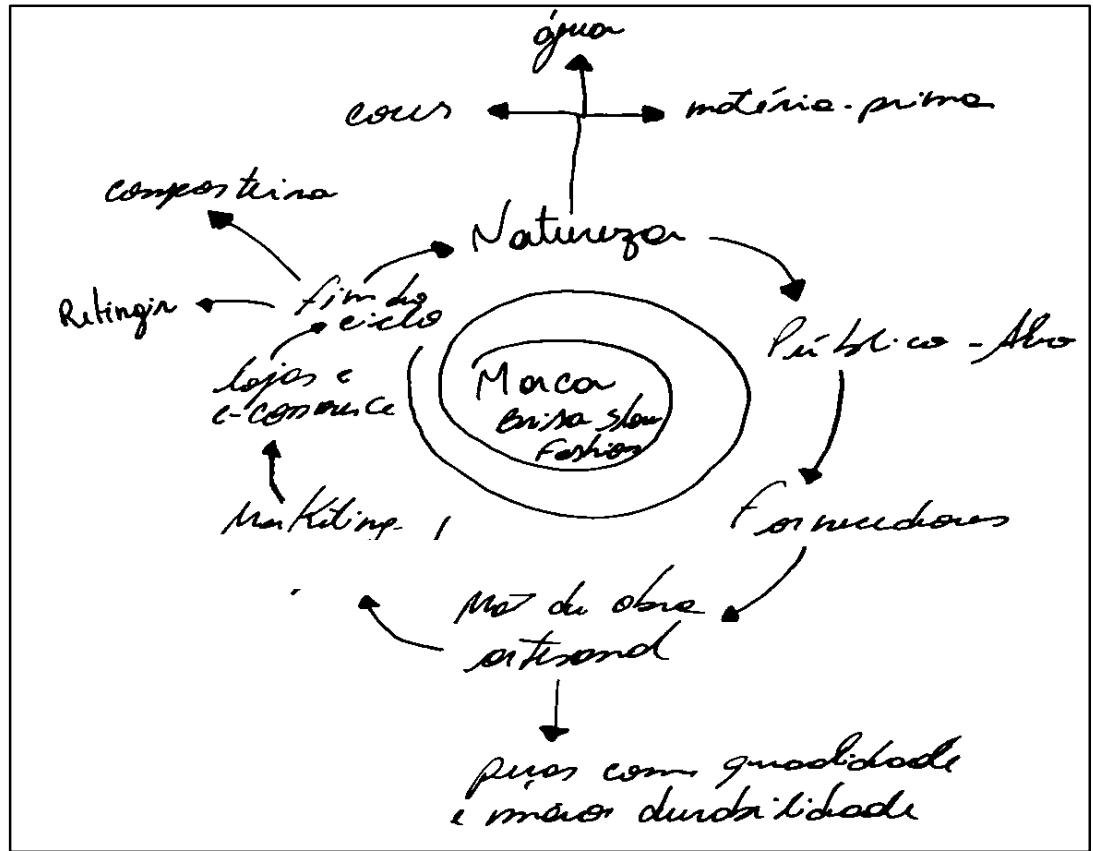

Com o propósito de continuar seu desenvolvimento sustentável da marca Brisa Slow Fashion tem possibilidades de agir estrategicamente nos cenários futuros traçados por Perini (2016). No primeiro cenário, "cultura para a sustentabilidade", a marca poderá desenvolver eventos de trocas, também conhecidos popularmente como eventos de escambo, no fim da vida do produto ao invés de realizar a compostagem das peças; também existe a possibilidade de realizar eventos de customização das peças, em técnicas manuais e artesanais como, por exemplo, o próprio tingimento natural junto aos clientes, passando os conhecimentos técnicos e gerando experiências únicas, novos significados às peças e a valorização das vivências em grupo.

O segundo cenário apresenta o "futuro tecnológico". A marca poderá realizar produtos sob demanda, de acordo com as necessidades dos clientes ou, ainda, ofertar possibilidades de mudanças ou adaptações. As coleções cápsula poderão ser comercializadas online, em plataformas de projetos sociais locais. Por exemplo: se uma pessoa deseja comprar determinado modelo de calça e mora na Europa, para enviar o produto terá muito gasto de energia. Sendo assim, as vendas pela plataforma da marca matriz serão constituídas por empresas parceiras 
que prezam as mesmas formas de produção e comercialização sustentável, dispondo de modelistas, costureiras, cooperativas que tenham técnicas manuais e artesanais para a realização do produto.

Contudo, o terceiro cenário, "sociedade em crise", apresenta questões de consumo e descarte exagerado, no qual a população necessitará de ajuda para reverter o contexto. Para tanto, a marca poderá reconfigurar os sistemas de marketing para chamar mais atenção em meio ao caos instaurado e, assim, conceder maior visão à sustentabilidade. Nas formas de comunicação ativa em e-books explicativos e educativos, sobre cada passo de desenvolvimento sustentável e social, poderá abordar possibilidades sustentáveis para reverter os cenários em crise. Já os produtos poderão ainda ser multifuncionais, propondo novas tecnologias sustentáveis de cuidados com a peça em suas lavagens e uso, para que a durabilidade seja estendida.

Para o quarto e último cenário, "território deteriorado", como as condições que a natureza e a sociedade se encontram são de extremo desgaste, a marca poderá optar por aumentar os nichos de marcado para atender, além do feminino, as linhas masculino e infantil. Poderá investir em tecnologias limpas, em uma gama tecidos inteligentes de fibras naturais, para que os consumidores possam aguentar o aquecimento global e as variações climáticas. Os tecidos também poderão ter proteção antipoluição, não necessitando de água para sua limpeza.

Outra questão social a ser abordada para esse cenário poderá ser o auxílio de interações locais para um sistema de vendas mais sustentável. A proposta é que em que cada peça de roupa comercializada uma porcentagem reverta para o reflorestamento, educação para o meio ambiente, limpeza dos rios e afluentes. Todas essas ações terão consentimento dos clientes que poderão escolher qual causa ajudar, conhecendo assim os princípios da marca e mais sobre a cultura da sustentabilidade.

Todas as propostas traçadas nos quatro cenários têm a possibilidade de agregar valores sustentáveis, 
significados eficazes em prol do ecossistema dos produtos e à marca. Com isso, pode-se propor a promoção da cultura da sustentabilidade a partir da consciência da sociedade, por meio de produtos e serviços condizentes com os contextos possíveis.

\section{CONSIDERAÇÕES FINAIS}

Pode-se constatar que o estudo de caso piloto da marca Brisa Slow Fashion, atendeu às possibilidades de ação e criação para produtos e serviços de design sustentáveis. Os cenários futuros apresentados na pesquisa de Perini (2016) trazem possibilidades de criação e apropriação de técnicas referentes ao desenvolvimento de produtos limpos.

As possibilidades de melhorias em meio aos cenários pessimistas, de acordo com as necessidades apresentadas nos contextos, trazem possibilidades de ações mais pontuais, muitas vezes ligadas à retomada de valores e à educação para a sustentabilidade.

Mesmo assim, é importante advertir que os fenômenos sociais complexos podem modificar os cenários traçados, assim como as modificações do ecossistema ou epifenômenos decorrentes de catástrofes naturais ou realizadas pelo homem.

Observou-se que as tendências sustentáveis e os cenários são partes fundamentais para o desenvolvimento de insights no objetivo de gerar produtos e serviços criativos, diferenciados e condizentes com o contexto. Propõe-se para projetos futuros desenvolver novos cenários, mediante outros públicos, para traçar o desenvolvimento de evoluções sociais frente os contextos locais. 
MORIN, Edgar. Introdução ao Pensamento Complexo. Trad. de Eliane Lisboa. 4. ed. Porto Alegre: Sulina, 2011.

PENN, Mark J. Microtendências. Trad. Adriana Rieche. Rio de Janeiro: BestSeller, 2008.

PERINI, Anerose. Design Estratégico Para A Mobilidade Urbana Sustentável Por Bicicleta Em Porto Alegre.

Dissertação (mestrado) - Universidade do Vale dos Sinos Programa de Pós- Graduação em Design, Porto Alegre, 2015. 122f.: il; $30 \mathrm{~cm}$.

PERINI , Anerose. Cenários Futuros Para o Design Sustentável. $12^{\circ}$ Colóquio de Moda - 9a Edição Internacional. III Congresso de Iniciação Científica em Design e Moda. João Pessoa, 2016.

POPCORN, Faith. O relatório Popcorn. Trad. de Outras Palavras. Rio de Janeiro: Campus; São Paulo: Publifolha, 1999.

POPCORN, Faith; Handt, Adam. Dicionário do Futuro: as tendências e expressões que definirão nosso comportamento. Trad. de Maurette Brandt. - Rio de Janeiro: Campus, 2002.

SALCEDO, Helena. Moda Ética Para Um Futuro Sustentável. São Paulo: G. Gili, 2014.

VIDA DE AMORA. Brisa Slow Fashion: uma marca consciente desde a origem da matéria prima até o consumidor final. Disponível em:

<http://vidadeamora.com.br/brisaslowfashion/>. Acesso em: 30 jan. 2018.

ZURLO, Francesco. Design Strategico. XXI Secolo, v. IV, Gli spazi e le arti. Roma: Enciclopedia Treccani. 2010. 